\title{
Regional connectivity drove bidirectional transmission of SARS-CoV-2 in the Middle East during travel restrictions
}

\author{
Edyth Parker ${ }^{1,15^{*}}$, Catelyn Anderson ${ }^{1,15}$, Mark Zeller ${ }^{1,15}$, Ahmad Tibi $^{2}$, Jennifer L. Havens ${ }^{3}$, \\ Geneviève Laroche ${ }^{4}$, Mehdi Benlarbi ${ }^{4}$, Ardeshir Ariana ${ }^{4}$, Refugio Robles-Sikisaka ${ }^{1}$, Alaa Abdel \\ Latif $^{1}$, Alexander Watts ${ }^{5}$, Abdalla Awidi ${ }^{6,7}$, Saied A. Jaradat ${ }^{8}$, Karthik Gangavarapu ${ }^{9}$, Karthik \\ Ramesh $^{1}$, Ezra Kurzban ${ }^{1}$, Nathaniel L. Matteson ${ }^{1}$, Alvin X. Han ${ }^{10}$, Laura D. Hughes ${ }^{11}$, Michelle \\ McGraw $^{1}$, Emily Spencer ${ }^{12}$, Laura Nicholson ${ }^{12}$, Kamran Khan ${ }^{5}$, Marc A. Suchard ${ }^{9,13}$, Joel O. \\ Wertheim ${ }^{14}$, Shirlee Wohl ${ }^{1}$, Marceline Côté ${ }^{4}$, Amid Abdelnour ${ }^{2}$, Kristian G. Andersen ${ }^{1,16}$, Issa \\ Abu-Dayyeh ${ }^{2,6,16,17^{*}}$ \\ ${ }^{1}$ Department of Immunology and Microbiology, The Scripps Research Institute, La Jolla, CA, USA \\ 2 Biolab Diagnostic Laboratories, Amman, Jordan \\ ${ }^{3}$ Bioinformatics and Systems Biology Graduate Program, University of California San Diego, La Jolla, CA, USA \\ ${ }^{4}$ Department of Biochemistry, Microbiology and Immunology, and Center for Infection, Immunity, and Inflammation, \\ University of Ottawa, Ottawa, ON, Canada \\ ${ }^{5}$ Bluedot, Toronto, Canada \\ ${ }^{6}$ Cell Therapy Center, The University of Jordan, Amman, Jordan \\ ${ }^{7}$ Thrombosis, haemostasis laboratory, School of Medicine, The University of Jordan, Amman, Jordan \\ ${ }^{8}$ Princess Haya Biotechnology Center, Jordan University of Science and Technology, Irbid, Jordan \\ ${ }^{9}$ Department of Human Genetics, David Geffen School of Medicine, University of California, Los Angeles, Los \\ Angeles, USA \\ ${ }^{10}$ Department of Medical Microbiology \& Infection Prevention, Amsterdam UMC, University of Amsterdam, \\ Amsterdam Institute for Infection and Immunity, Amsterdam, the Netherlands \\ ${ }^{11}$ Department of Integrative, Structural and Computational Biology, The Scripps Research Institute, La Jolla, CA \\ 92037, USA \\ ${ }^{12}$ Scripps Research Translational Institute, La Jolla, USA \\ ${ }^{13}$ Department of Biostatistics, Fielding School of Public Health, University of California, Los Angeles, Los Angeles, \\ CA, USA \\ ${ }^{14}$ Department of Medicine, University of California San Diego, La Jolla, CA, USA \\ ${ }^{15}$ These authors contributed equally \\ ${ }^{16}$ Senior author \\ ${ }^{17}$ Lead contact \\ *Correspondence: eparker@scripps.edu; i.abudayyeh@biolab.jo
}


medRxiv preprint doi: https://doi.org/10.1101/2022.01.27.22269922; this version posted January 28, 2022. The copyright holder for this preprint (which was not certified by peer review) is the author/funder, who has granted medRxiv a license to display the preprint in perpetuity.

It is made available under a CC-BY-ND 4.0 International license .

\section{Highlights:}

1. Regional connectivity drove SARS-CoV-2 introduction risk in Jordan during the period travel restrictions were in place in genomic and travel data.

2. Land-based travel rather than air travel disproportionately drove introduction risk during travel restrictions.

3. High regional connectivity disproportionately drove Jordan's export risk, with significant contribution from land-based travel.

4. Regional transmission dynamics were underestimated in genomic data due to unrepresentative sampling.

\section{Summary}

Regional connectivity and land-based travel have been identified as important drivers of SARSCoV-2 transmission. However, the generalizability of this finding is understudied outside of wellsampled, highly connected regions such as Europe. In this study, we investigated the relative contributions of regional and intercontinental connectivity to the source-sink dynamics of SARSCoV-2 for Jordan and the wider Middle East. By integrating genomic, epidemiological and travel data we show that the source of introductions into Jordan was dynamic across 2020, shifting from intercontinental seeding from Europe in the early pandemic to more regional seeding for the period travel restrictions were in place. We show that land-based travel, particularly freight transport, drove introduction risk during the period of travel restrictions. Consistently, high regional connectivity and land-based travel also disproportionately drove Jordan's export risk to other Middle Eastern countries. Our findings emphasize regional connectedness and land-based travel as drivers of viral transmission in the Middle East. This demonstrates that strategies aiming to stop or slow the spread of viral introductions (including new variants) with travel restrictions need to prioritize risk from land-based travel alongside intercontinental air travel to be effective.

\section{Introduction}

Global pathogen surveillance programs have generated an unprecedented number of SARSCoV-2 sequences since the start of the COVID-19 pandemic. This has enabled large- and finescale characterization of transmission dynamics. ${ }^{1-4}$ Several studies have highlighted regional and neighboring countries as major sources of transmission, with shorter-distance, land-based travel identified as an important driver of viral spread. ${ }^{2,5-8}$ However, the generalizability of these findings remains understudied in regions with sparser sampling and more restricted freedom of movement than Europe. In particular, it is not clear what the relative contributions of regional and intercontinental connectivity are to the source-sink dynamics for most regions globally. It is also unclear how these relationships change over time in response to the unprecedented restrictions on human mobility from travel restrictions and comprehensive curfews during the pandemic in these regions. It is important to understand how the sources of transmission change over time 
medRxiv preprint doi: https://doi.org/10.1101/2022.01.27.22269922; this version posted January 28, 2022. The copyright holder for this preprint (which was not certified by peer review) is the author/funder, who has granted medRxiv a license to display the preprint in perpetuity. It is made available under a CC-BY-ND 4.0 International license .

and in response to mobility restrictions in order to evaluate the effectiveness of interventions such as border closures.

Jordan is located in the northern Arabian Peninsula, bordered by Syria, Iraq, Saudi Arabia, Palestine and Israel, and has strong sociopolitical, cultural and economic ties with other countries in the Middle East and North Africa region (MENA, here referred to as the Middle East). The Middle East accounted for approximately $60 \%$ of in-bound air travel volume to Jordan in the prepandemic months in addition to high volumes of private and commercial land-based travel. Jordan banned all non-essential travel across its land, air and maritime borders from 17 March 2020 to early September 2020. The closure was part of a stringent package of non-pharmaceutical interventions (NPIs) implemented in response to an increase in SARS-CoV-2 cases in returning travelers and their direct contacts after the virus was first detected in the country on 2 March 2020. Notably, Jordan implemented an institutional 14-day hotel-quarantine in mid-March, which was only lifted in September $2020{ }^{9}$ Travel volume declined by approximately $96 \%$ in response to the restrictions. During this period, Jordan largely maintained essential travel and commercial transport with only Middle Eastern countries. This suggests a potential shift in transmission to and from Jordan (bidirectional transmission) from global to more regional source-sink dynamics during this period. However, the contribution of regional connectivity to viral spread is currently largely obscured by undersampling in the Middle East region. There are only a select number of studies investigating the genomic epidemiology of SARS-CoV-2 in Middle Eastern countries, with limited temporal and geographic scope..$^{10-16}$

In this study, we characterize the genomic epidemiology of SARS-CoV-2 in Jordan from March 2020 to the end of its second wave (May 2021). We focus on Jordan's connectivity to the Middle East region as a driver of its transmission dynamics. Towards this, we reconstruct the timing and origin/destination of bidirectional SARS-CoV2 transmission for Jordan by integrating phylogeographic reconstructions, travel data, and an incidence-informed introduction and export intensity index. We assess the robustness of our inferred source-sink dynamics over time across three different downsampling strategies developed to account for sparse sampling globally but particularly in the Middle East. We show that the profile of viral introductions was dynamic during the pandemic, and that it shifted from intercontinental air travel-driven risk from Europe to regional risk mediated by large volumes of land-based freight transport during the period of travel restrictions. We also show that connectivity to the Middle East disproportionately drove Jordan's export risk, with significant contribution from land-based travel. We found that this signal was obscured in the genomic data owing to global and regional sampling biases. Our findings emphasize the need for strategies aiming to stop or slow the spread of viral introductions (including new variants) with travel restrictions to prioritize management of risk from regional landbased travel alongside intercontinental air travel restrictions. 


\section{Results}

\section{Early introductions into Jordan were predominantly sourced from Europe and successfully contained by NPIs}

We investigated the major sources of introductions into Jordan and the shifts in the introduction profile over time, with a focus on the relative contribution of Middle Eastern (defined in Methods) and non-Middle Eastern countries. Towards this, we generated 579 sequences from 16 March 2020 to 31 December 2020 (encompassing the phase of epidemic containment and the first epidemic wave) from routine diagnostic tests performed by Biolab Diagnostic Laboratories in four governorates including Amman, Irbid and Zarqa (Figure 1 A, B). Our sampling was predominantly concentrated in the densely populated Amman and Irbid, which were also the epicenters of the outbreak across both waves (Figure 1D).

To determine the profile of introductions in Jordan, we reconstructed the timing and pattern of geographic transitions into and out of Jordan across the full posterior of Bayesian phylogeographic reconstructions. This approach accounts for uncertainty in the phylogenies and migration histories associated with low sequence variability and sampling biases. ${ }^{17}$ We assessed the robustness of our findings across three different downsampling strategies developed to minimize the effect of sampling biases, particularly undersampling in the Middle East. Of the Middle Eastern region, only Israel and Qatar sampled $>1 \%$ of cumulative cases up to October 2021. Notably, Syria and Yemen had no publicly available sequences, with fewer than 150 respective sequences from Libya, Algeria, Lebanon, Iraq, Tunisia, and Palestine during the study period (Figure 1E). Our downsampling strategies included an epidemic incidence-proportional downsampling (EII), an incidence-informed strategy enriching for Middle Eastern sequences (RE) and an importation intensity-proportional downsampling (III) (see Methods).

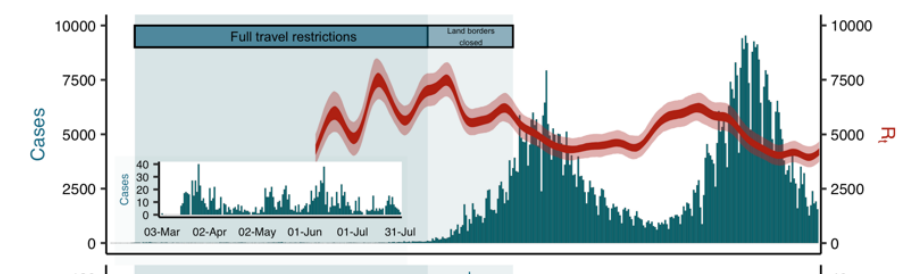

D

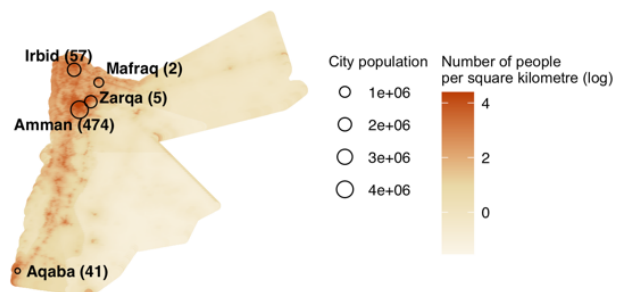

в

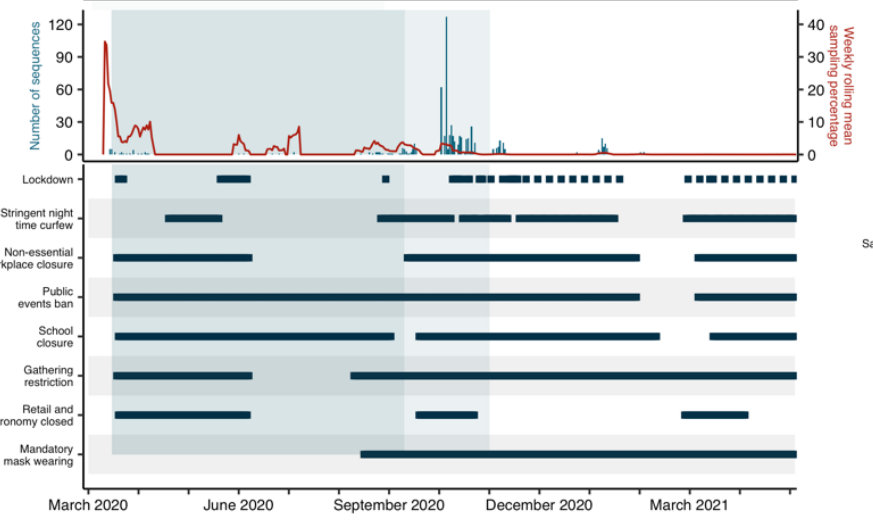

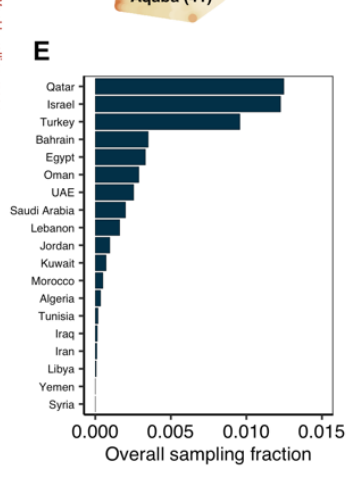

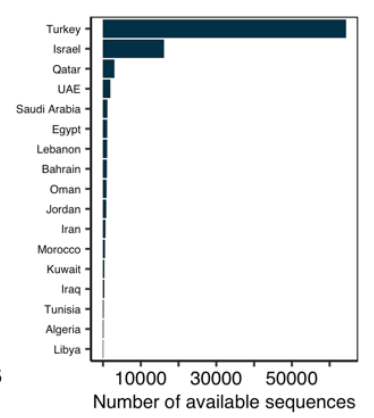


medRxiv preprint doi: https://doi.org/10.1101/2022.01.27.22269922; this version posted January 28, 2022. The copyright holder for this preprint (which was not certified by peer review) is the author/funder, who has granted medRxiv a license to display the preprint in perpetuity.

It is made available under a CC-BY-ND 4.0 International license .

Figure 1: Investigating the first year of the SARS-CoV-2 pandemic in Jordan. A) Reported daily cases in Jordan (bar graph, left axis) including inset of early pandemic months as well as time-varying effective reproduction number (ribbon, right axis). B) Number of sequences generated in this study from Jordan (bar graph, left axis) and weekly rolling mean sampling fraction for Jordan (line, right axis). C) Timeline of non-pharmaceutical interventions in Jordan (see Methods for definitions). D) Geographic distribution of sequences generated in the current study, relative to population density of Jordan and its major sampled cities. E) Overall sampling fraction for all Middle Eastern countries and number of publicly available SARS-CoV-2 sequences on GISAID for Middle Eastern countries.

Our phylogeographic reconstructions demonstrated that the likely source of introductions into Jordan was dynamic over the course of the pandemic, with early introductions predominantly sourced from Europe (Figure 2A). Overall, we estimated a lower bound of 28 [posterior median, 95\% HPD 25 - 31] independent introductions into Jordan for the sampled genomic data, with estimates robust to downsampling and randomization (Figure 2B). We estimated that approximately half of the sampled introductions (14 [posterior median, 95\% HPD 12-16] occurred before the travel restrictions were imposed on the 17th of March, with the majority of sampled introductions occurring in the month of March (Figure 2C). We found that this was largely driven by the high number of singletons sampled during this period, with limited onward transmission at the time (Figure 2A).

To understand the lineage diversity across Jordan's waves, we assigned lineages to the sequences using Pangolin. ${ }^{18}$ We sampled a higher number of distinct lineages in the early months of the pandemic, in line with multiple independent introductions with limited onward transmission (Figure 2D). Our early (March - May 2020) sequences represented nine lineages, though the majority were classified as B.1 and B.1.1, the globally dominant lineages at the time. ${ }^{19}$ We found that early introduction events predominantly originated from Europe across all three downsampling strategies (Figure 2B, C), consistent with the large epidemic incidence at the time (Supplementary figure 1 ) but also early pandemic sampling biases. ${ }^{1}$

Jordan successfully contained community transmission for the first half of 2020 (Figure 1A). We found that the high number of introductions without sampled onward transmission in our phylogeographic analyses supported the epidemiological data that showed relatively high introduction rates contained by rapid and comprehensive mitigation strategies (Figure 1C). We found that Jordan had a prolonged phase of low incidence after the first cases were detected in early March 2020. The weekly rolling average case numbers remained below 25 until the middle of August 2020. Alongside travel restrictions, the epidemic was controlled with strictly enforced adherence to NPIs including a comprehensive curfew, strict gathering restrictions and school, retail and non-essential workplace closure implemented on 17 March 2020 (Figure 1C).

In our phylogeographic reconstructions, we found no evidence that SARS-CoV-2 was circulating cryptically in Jordan before identification of the first local cases. The first sampled introduction into Jordan from Europe occurred in mid-to-late February to early March across all datasets, consistent with epidemiological evidence that the first case returned from Italy (the epicenter of the European outbreak at the time) two weeks prior to detection on 2nd of March in quarantine (Supplementary figure 2). This suggests that Jordan had an efficient early surveillance and case identification program that initially contained the epidemic. 
A

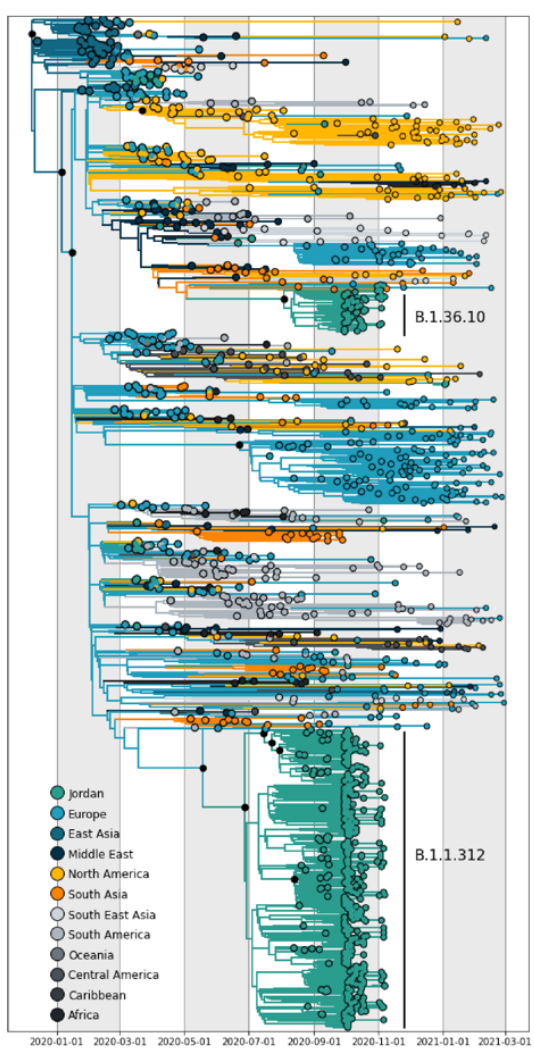

B

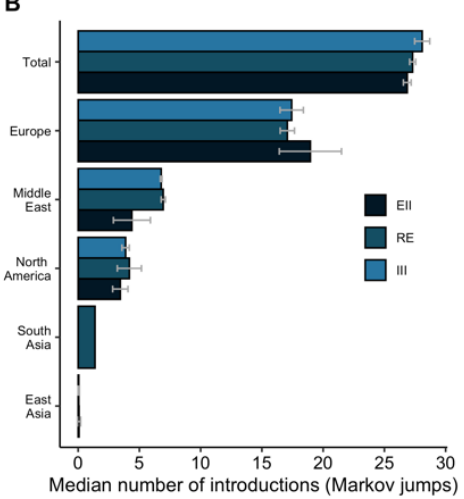

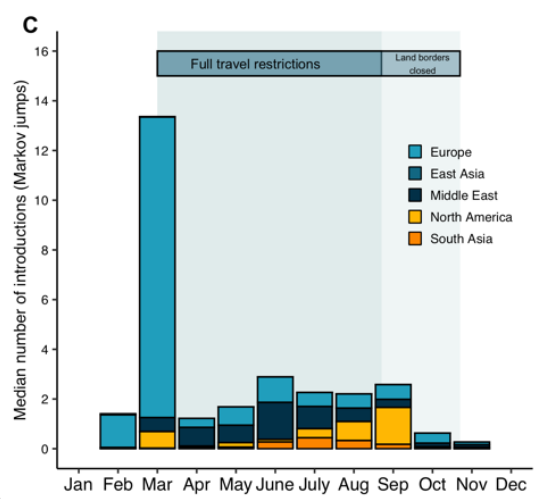

$\mathbf{D}_{\mathscr{E}}$

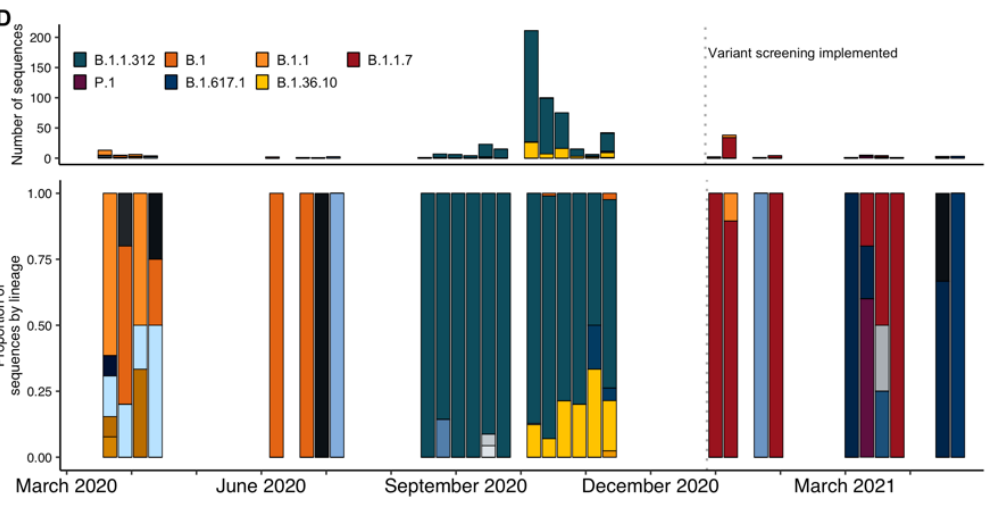

Figure 2: Phylogeographic analysis of SARS-CoV-2 in Jordan. A) A representative time-calibrated phylogeny. Branches are colored by region-level geographic state reconstruction. Internal nodes annotated with black point represent posterior support $>0.75$. B) The estimated number of introductions into Jordan from source regions summarized across three replicates for each of the three downsampling strategies annotated in color. Ell: Epidemiological incidence informed; RE: Regional enrichment; III: Introduction Intensity Index informed - see Methods for full definition. C) Posterior median number of introductions into Jordan binned by month from each region, summarized across all datasets. D) Lineage frequency profile over time for 579 sequences generated in this study, classified by the Pangolin nomenclature. Only major lineages in Jordan and variants of concern are listed in the legend. Dashed line indicates when variant screening was implemented.

\section{The geographic origin of introductions into Jordan shifted to regional seeding during the period of travel restrictions}

In our phylogeographic analyses of the major sources and timing of introductions into Jordan, we found that the Middle East was the second largest source of introductions (Figure 2B,C). We found that the number of introductions from the Middle East increased relative to Europe across all datasets for the period travel restrictions were in place (mid-March to September 2020), suggesting a shift to regional seeding during the period of travel restrictions (Figure 3A). This trend was consistent across the downsampling strategies and randomizations (Supplementary figure 3).

To understand how undersampling in the Middle East was likely to affect the number of regional transmission events observed, we developed three downsampling strategies, including two (III and RE, see Methods) that enriched for samples from the Middle East, and performed our phylogeographic analyses on three random replicates of each. The effect of downsampling on 
medRxiv preprint doi: https://doi.org/10.1101/2022.01.27.22269922; this version posted January 28, 2022. The copyright holder for this preprint (which was not certified by peer review) is the author/funder, who has granted medRxiv a license to display the preprint in perpetuity. It is made available under a CC-BY-ND 4.0 International license .

source-sink inferences was most pronounced for the Middle East estimates (Figure 2B). We found that the estimated number of introductions from the Middle East were higher in III and RE datasets that had more representation from the region, highlighting how sampling biases can result in underestimation of transmission from more sparsely sampled regions (Figure 2B).

We estimated a low number of introductions during the period of travel restrictions, which was expected given low incidence and therefore minimal sampling (Figure 2C, D). Starting in August 2020, we observed a strong selective sweep to the B.1.1.312 lineage, which fits with limited introductions due to travel restrictions and the onset of community transmission (Figure 2D). In our phylogeographic analyses of the B.1.1.312 lineage, we found that B.1.1.312 likely emerged in Jordan (see Supplementary Information for our full phylogeographic analyses). The lineage notably has the Q957L mutation in a conserved heptad repeat region (HRR) of the S2 subunit of the spike glycoprotein. The HRR has been implicated in the conformational changes required for cell-cell fusion and viral entry for SARS-CoV-1 and HIV. ${ }^{20,21}$ We characterized the phenotypic relevance of the Q957L substitution in silico and in vitro and found no functional advantage for Q957L, despite previous claims (see Supplementary Information Figure 2). ${ }^{22}$

The number and origin of viral introductions estimated from genomic data is fundamentally dependent on the sample taken. To mitigate this sample-dependence, we investigated which countries are most likely to act as a source of transmission based on their connectivity to Jordan by quantifying changes in air and land travel to Jordan over time. We obtained travel data from the International Air Transport Association (IATA) and the Customs Agency of the Hashemite Kingdom of Jordan. All non-essential air travel to and from Jordan was banned on 17 March 2020. We found that the travel restrictions were very efficient, with international air passenger flow decreasing by $96 \%$ through April 2020 (Figure 3B). We found that approximately $85 \%$ of incoming air passengers originated from countries in the Middle East from March to early September 2020, when travel restrictions were in place (Figure 3B,C). This strongly supports regional connectivity as the dominant source of risk from air travel during this period, which is consistent with the introductions we observed in our phylogeographic reconstructions (Figure 3A).

To better understand how regional connectivity drove introduction risk, we also investigated changes in land-based travel from neighboring countries in response to border closures. In response to travel restrictions, we found that land-based travel volume declined by $99 \%$ starting in April 2020 for private vehicles and buses, predominantly originating in Saudi Arabia (Figure 3D). We found that land-based travel volume remained at $0.06-3.6 \%$ of pre-pandemic volume through December 2020 (Figure 3D). Only select border crossings with Saudi Arabia, Israel and Palestine opened from late October 2020, allowing 100-150 pre-registered travelers subject to COVID testing and home quarantine. ${ }^{23}$ This suggests that introduction risk from private landbased travel was limited in 2020. Alongside private land-based travel, Jordan has high levels of commercial truck (freight) volume in bidirectional transit with its neighboring countries across multiple industries. We found that incoming truck volume declined to $50-60 \%$ of the pre-pandemic baseline in April and May but recovered to largely pre-pandemic levels from July onwards (Figure 3D). We found that Saudi Arabia had the highest number of incoming trucks, followed by Iraq and 
medRxiv preprint doi: https://doi.org/10.1101/2022.01.27.22269922; this version posted January 28, 2022. The copyright holder for this preprint (which was not certified by peer review) is the author/funder, who has granted medRxiv a license to display the preprint in perpetuity.

It is made available under a CC-BY-ND 4.0 International license .

Israel-Palestine. The sustained levels of freight transport during the travel restrictions strongly suggest that a lot of the introduction risk in the region may be mediated by freight trade.

A

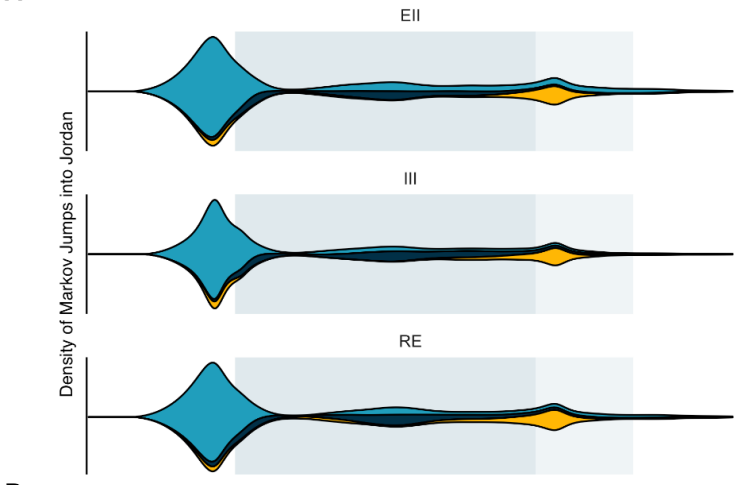

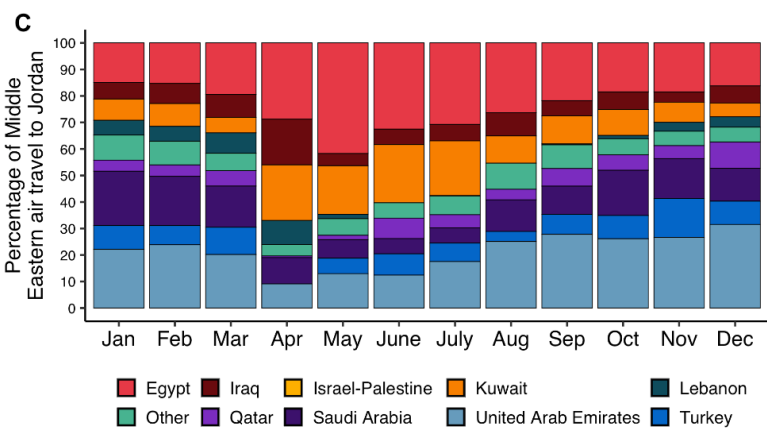

D

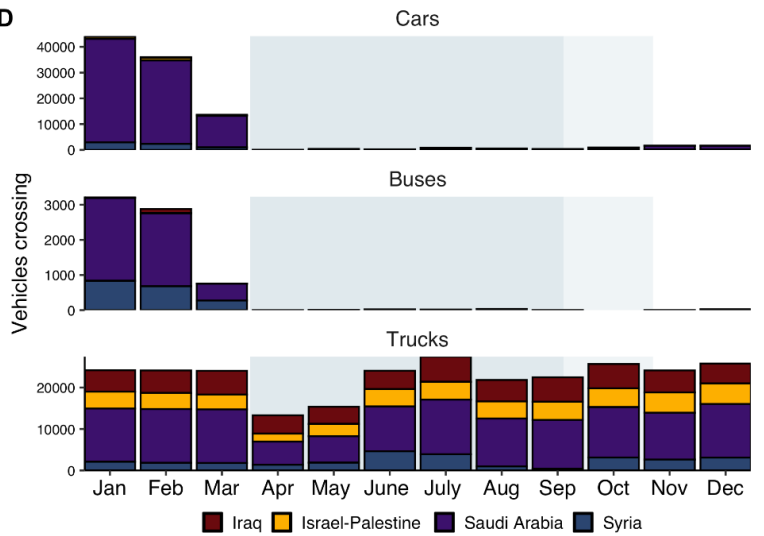

Figure 3: Dynamic introduction risk for Jordan shifts to regional seeding during the period of travel restrictions in 2020. A) The density of estimated introductions (Markov jumps) into Jordan over time from source regions by downsampling strategy (EII, III, RE) summarizing three replicates each. See Supplementary figure 3 for all replicates. Ell: Epidemiological incidence informed; RE: Regional enrichment; III: Introduction Intensity Index informed. For legend see B. B) Volume of monthly air passengers destined for Jordan across 2020 by region (bar, left axis) and percentage of incoming volume originating from the Middle Eastern region (line, right axis). C) Percentage of incoming air travel from the Middle East by country across 2020. D) Incoming land-based travel by vehicle type for each bordering country across 2020. Time period of land border closure (lighter blue) annotated.

\section{The geographic origin of introductions into Jordan shifted again after travel restrictions were lifted}

In our phylogeographic analyses of the sources and timing of introductions into Jordan, we found that viral introductions from non-Middle Eastern countries increased again after travel restrictions and institutional quarantine were lifted on $8^{\text {th }}$ and $23^{\text {rd }}$ September 2020 respectively (Figure 3A). In particular, we found that the number of introductions from North America increased starting in September, though the absolute estimated number remained low. In the travel data, we found that passenger volume recovered to only $15-22 \%$ of the pre-pandemic baseline after travel restrictions were lifted in early September (Figure 3B). We also found that non-Middle Eastern air travel increased from 15 to $25 \%$ of total volume, predominantly driven by incoming travelers from the USA, which suggests an increased introduction risk from intercontinental air travel (Figure 3B). Overall, we found little evidence of introduction risk into Jordan from regions other 
medRxiv preprint doi: https://doi.org/10.1101/2022.01.27.22269922; this version posted January $28,2022$. The copyright holder for this preprint (which was not certified by peer review) is the author/funder, who has granted medRxiv a license to display the preprint in perpetuity.

It is made available under a CC-BY-ND 4.0 International license .

than Europe, North America and the Middle East across all phylogeographic reconstructions and all of the epidemic phases (Supplementary table 1 ).

The introduction of B.1.1.7 initiated the larger second epidemic wave in Jordan, with cases surging from the end of January 2021 and peaking in mid-March 2021 at over 9,500 cases a day (Figure 1A). We identified B.1.1.7 (Alpha) variant sequences by S-gene target failure (SGTF) screening from December 2020 to January 2021 and performed an independent phylogeographic analysis of these sequences along with a globally representative set of background sequences (see Methods) (Supplementary figure 4). We estimated that the first introduction of B.1.1.7 into Jordan occurred in late November, with a minimum of 17 sampled introductions [posterior median, $95 \%$ HPD 12-22] in mid-to-late December 2021. All of the introductions originated from Europe, supporting the shift in the origin of introduction dynamics after the travel restrictions were lifted (Figure 3A). This is consistent given the high incidence of cases during the second wave in the UK at this time, which was driven by the local emergence of the B.1.1.7 variant in September 2020. This is also consistent with the introduction of the B.1.1.7 variant into several European countries within months of its first detection in the UK (Supplementary figure 4). ${ }^{24}$

\section{Regional connectivity drove import risk into Jordan during the period of travel restrictions}

Introduction risk is not just driven by connectivity but is a product of the number of travelers to Jordan (i.e. connectivity) and the number of cases in the connected countries likely to travel. To account for the size of the epidemics in countries connected to Jordan over time, we integrated the travel data with epidemic incidence data to quantify the importation (introduction) intensity index (II). ${ }^{2}$ The II quantifies the temporal trend in the daily estimated number of introductions into Jordan from source countries (see Methods).

We found that the dynamic II profile was highly consistent with the timing of the introductions from our phylogeographic reconstructions (Figure 4A). The II peaked in early March 2020, driven by air travel from European countries experiencing high epidemic incidence ${ }^{7}$. We found that regional countries with land, air and maritime connectivity with Jordan were not dominant source countries prior to the travel restrictions implemented on $17^{\text {th }}$ of March despite high travel volumes as these countries largely had relatively lower incidence at the time (Supplementary figure 1). ${ }^{25}$ We found that European countries' dominance in the II profile prior to the travel restrictions was consistent with the high number of introductions from Europe in March estimated in our phylogeographic reconstructions (Figure 3A). We found that the total II expectedly reduced sharply in response to travel restrictions in March 2020, declining by approximately $65 \%$ from its early peak driven by Europe in March to the Middle East regional-driven peak during travel restrictions (17 March - 8 September 2020) (Figure 4A). The source risk profile shifted to Middle Eastern countries from late March till September, as these regional countries maintained higher volumes of both land and air travel into Jordan and experienced relatively delayed peak incidence with some exceptions including Israel and Iran. ${ }^{25}$ The temporal shift to regional risk in the II was consistent with the shift to higher relative regional seeding we estimated during the travel restrictions in the phylogeographic reconstructions (Figure 3A). Saudi Arabia had the highest II of the regional 
medRxiv preprint doi: https://doi.org/10.1101/2022.01.27.22269922; this version posted January 28, 2022. The copyright holder for this preprint (which was not certified by peer review) is the author/funder, who has granted medRxiv a license to display the preprint in perpetuity. It is made available under a CC-BY-ND 4.0 International license .

countries across the entire period of travel restrictions, followed by Iraq and Israel-Palestine. This suggests that connectivity to Saudi Arabia posed the highest introduction risk to Jordan during the period travel restrictions were in place. To narrow down the source of risk, we partitioned the II by travel type (air, land) and vehicle type (trucks, private cars and buses) (Figure 4B). We found that the introduction risk from regional countries was predominantly driven by land-based travel, and in particular truck volume.

We found that the II for non-regional countries, particularly the USA, increased after air travel restrictions were lifted in September 2020 (Figure 4A). The increased II for the USA was consistent with the increase in introductions we observed from Northern America from September onwards in the genomic dataset. Consistent with the phylogeographic reconstructions, there was a negligible introduction risk into Jordan from regions other than Europe, North America and the Middle East.

To determine the effect of the border closures on reducing transmission risk from imported cases in Jordan, we quantified the II under the assumption that travel volume was maintained at the levels of January-February 2020 for March to September (see Methods) (Figure 4C). We conclude that the Middle East, and in particular Saudi Arabia, had the largest reduction in absolute introduction risk during the period of travel restrictions, which was driven by the reduction of large volumes of private car and bus travel (Figure 4D). This supports our findings that land-based travel is a major driver of introduction risk, and strongly suggests that introduction risk can be effectively reduced by interventions such as land border closures. Notably, introduction risk was not eliminated as the border closures were not comprehensive and commercial land-based travel was continued throughout this period as previously discussed (Figure 4A, B). The reduction in non-Middle Eastern countries' aggregate II was driven almost exclusively by the reduced introduction risk from the USA, as well as European countries during the early months. This supports previous evidence that there is negligible introduction risk to Jordan outside of Europe, North America and the Middle East. 
medRxiv preprint doi: https://doi.org/10.1101/2022.01.27.22269922; this version posted January 28, 2022. The copyright holder for this preprint (which was not certified by peer review) is the author/funder, who has granted medRxiv a license to display the preprint in perpetuity.

It is made available under a CC-BY-ND 4.0 International license .

A

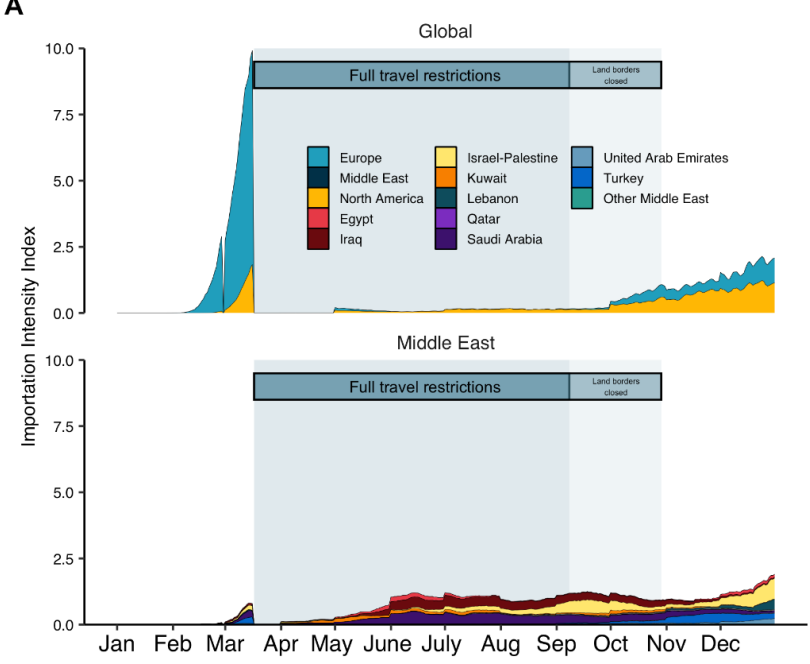

C
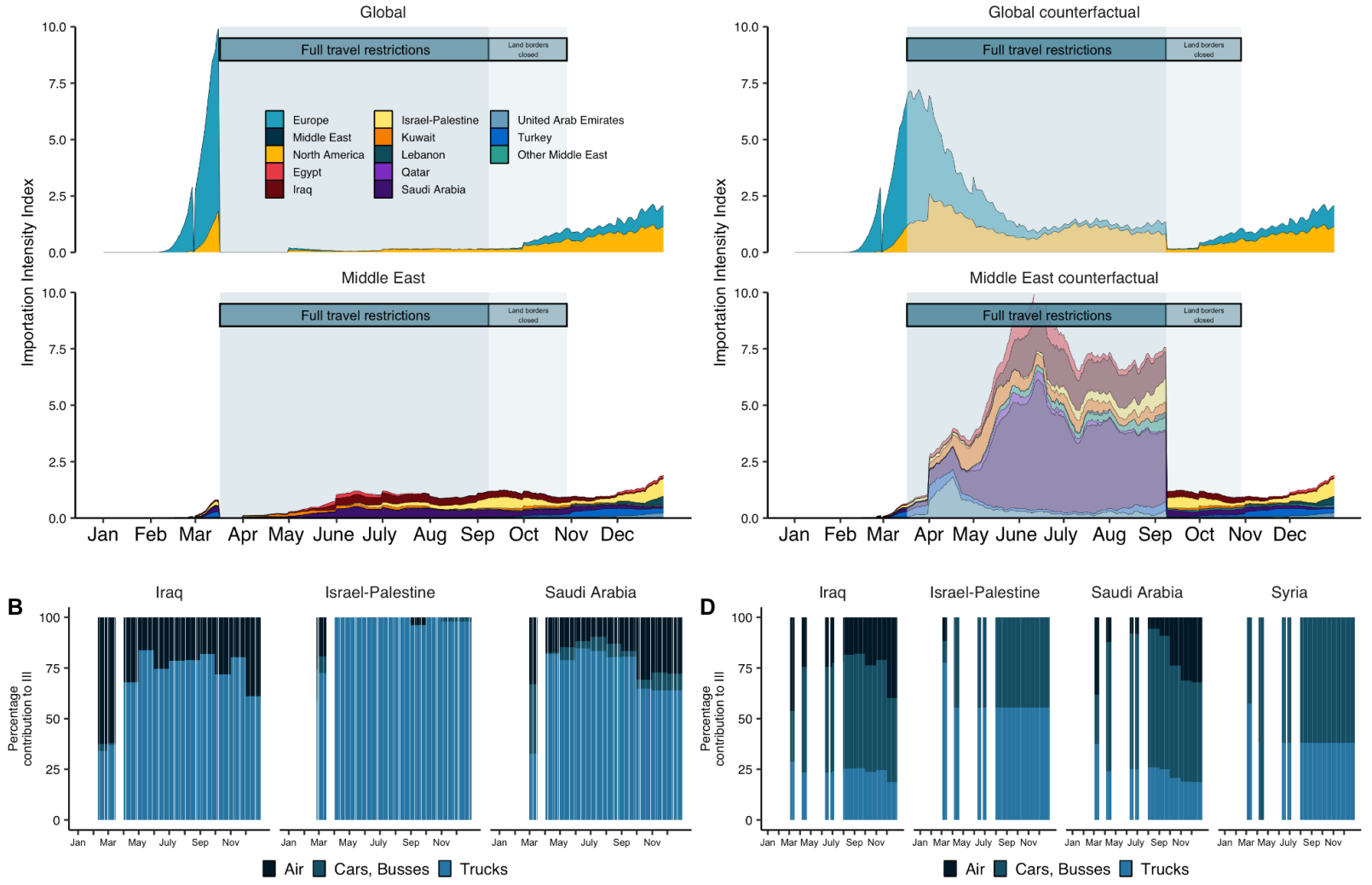

Figure 4: Land-based regional connectivity drives introduction risk during the period of travel restrictions for Jordan. A) Estimated introduction (importation) Intensity Index (II) for 2020, divided into the Middle East and nonMiddle Eastern countries (Global). Countries grouped by region, except Middle Eastern countries in the bottom panel of A, which are country-level. Legend in A also applies to C. B) Contribution of land and air travel to II in panel A for highest ranked regional countries. C) The effect of travel restrictions on introduction risk. Counterfactual estimated Introduction Intensity Index (II) for 2020 were travel restrictions not implemented, assuming travel volumes of JanuaryFebruary 2020 were extended from March to September. The counterfactual II is annotated in faded colors. Legend of A applied to C. D) Contribution of land and air travel to counterfactual II in panel $\mathrm{C}$ for highest ranked regional countries.

\section{Undersampling in the Middle East region obscures Jordan's role as a source of regional transmission}

The transmission dynamics of SARS-CoV-2 in the Middle East are obscured by uneven sampling. Using our dataset of genomes from Jordan, we aimed to understand transmission in the Middle East region by analyzing Jordan's role as a source of introductions to other Middle Eastern countries relative to the rest of the world. We were also interested in how unrepresentative sampling in these populations potentially obscured regional dynamics evidenced by other data sources such as travel data.

To understand what countries were most connected to Jordan, we quantified changes in outbound land and air travel obtained from IATA and Jordan's customs agency for 2020. We estimated that $72 \%$ of air travel volume during the months of July to December 2020 (from the putative onset of local transmission - see Supplementary Information - to the end of the first wave ) was bound for Middle Eastern countries, again highlighting the high level of regional connectivity (Figure 
medRxiv preprint doi: https://doi.org/10.1101/2022.01.27.22269922; this version posted January 28, 2022. The copyright holder for this preprint (which was not certified by peer review) is the author/funder, who has granted medRxiv a license to display the preprint in perpetuity. It is made available under a CC-BY-ND 4.0 International license .

5A,B). The USA was the only non-regional country in the top ten out-bound destinations. We found that land-based travel from Jordan decreased 99.9\% towards April 2020, only recovering to $5 \%$ of the baseline by December 2020 . The majority of land-based travel during Jordan's first wave flowed to Saudi Arabia and Syria (Figure 5C). We found that the out-bound flow of freight transport (truck volume) declined to $51-58 \%$ of the pre-pandemic baseline in April-May 2020 but recovered to baseline by June 2020. The majority of freight transport was destined for Saudi Arabia. This was consistent with our analyses of introduction risk, with a large proportion of regional connectivity and therefore export risk from Jordan driven by freight transport.

In our phylogeographic analyses of viral exports from Jordan, we only found evidence that Jordan acted as a source to Middle Eastern countries in the B.1.1.312 dataset, which is Jordan's most sampled lineage owing to its predominance during its first wave. We only detected single exports of B.1.1.312 to Palestine, Egypt and Turkey respectively (See Supplementary information). We also did not find strong similarity in the lineage composition (see Methods) between Jordan and other Middle Eastern countries over time (Figure 5D). However, it's highly unlikely that we would identify many transmission events as regional sampling fractions were particularly low at the time of Jordan's peak incidence (Supplementary figure 5). To overcome these sampling biases, we quantified Jordan's exportation risk based on connectivity in the travel data and Jordan's epidemiological curve.

We investigated which countries were most likely to act as a sink for Jordan's viral exports across time by estimating Jordan's exportation intensity index. As with the II, this measure accounted for Jordan's changing epidemic incidence across time in combination with the number of outbound land and air passengers to seed countries. We observed that regional connectivity drove Jordan's role as a potential source of SARS-CoV-2 transmission. We found that the estimated exportation intensity index peaked in November after onset in September, as it was informed by the epidemic incidence of the first wave in Jordan (Figure 1A). We found that exportation risk was far higher for Middle Eastern countries, collectively as well as individually, despite recommencement of intercontinental air travel in early September. The exportation intensity index was the highest for Saudi Arabia across time, driven predominantly by high volumes of freight transport which also holds for all other neighboring countries (Figure 5E-F). The only non-regional country with a nonnegligible exportation intensity index was the United States. This is consistent with the number of exports of B.1.1.312 and minor clade B.1.36.10 to the USA we observed during Jordan's first wave in the phylogeographic reconstructions (See Supplementary information). 

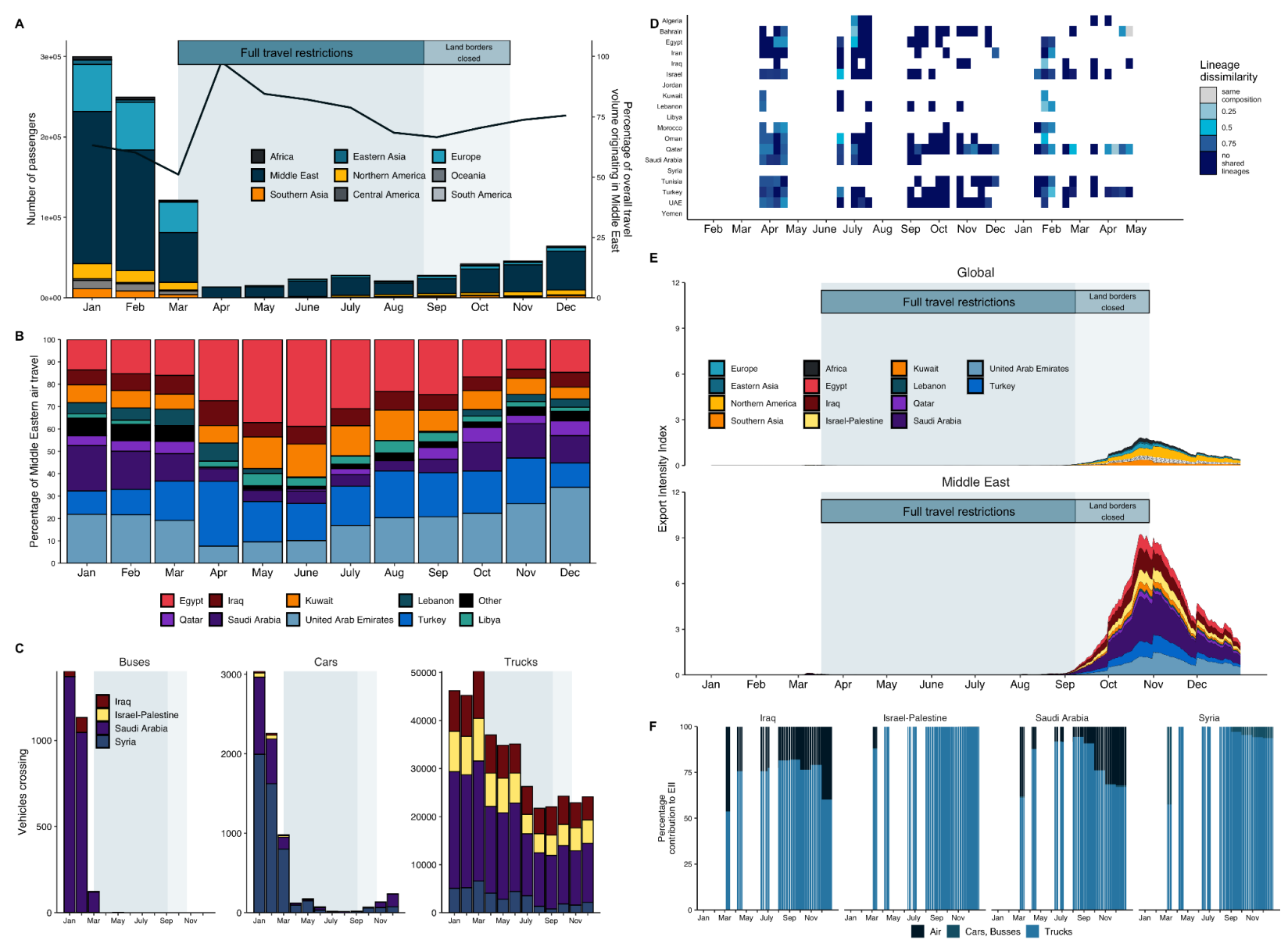

Figure 5: Land-based regional connectivity drives export risk from Jordan in 2020. A) Volume of monthly air passengers traveling from Jordan across 2020 by region (bar, left axis) and percentage of outgoing volume destined for the Middle Eastern region (line, right axis). B) Percentage of outgoing air travel to the Middle East by country across 2020. C) Outgoing land-based travel by vehicle type for each bordering country across 2020 . Time period of land border closure (light blue) annotated. D) Dissimilarity between weekly binned lineage frequency profiles as presence-absence of lineages between Jordan and its Middle Eastern neighbors by Bray-Curtis dissimilarity. Bray-Curtis dissimilarity is bound between 0 and 1 , with 0 indicating the countries have the same composition and 1 indicates countries do not share any lineages. E) Estimated Exportation Intensity Index for 2020. F) Contribution of land and air travel to the Ell of Jordan's neighboring countries.

\section{Discussion}

We integrated genomic, epidemiological and travel data to investigate the source-sink dynamics of SARS-CoV-2 in Jordan in the context of Jordan's connectivity to the wider Middle East. Our results show how the source risk profile of viral introductions into Jordan was dynamic over the pandemic. It shifted from a high number of introductions from Europe in the early pandemic months to lower levels of regional introductions when the travel restrictions were in place in both the phylogeographic reconstructions and the introduction intensity index. We also showed that land-based travel, and in particular freight transport, rather than air travel disproportionately drove introduction risk during this period. Consistent with the introduction risk profile, we showed that high regional connectivity disproportionately drove Jordan's export risk, with significant contribution from land-travel. Our findings for the Middle East are consistent with previous studies 
medRxiv preprint doi: https://doi.org/10.1101/2022.01.27.22269922; this version posted January 28, 2022. The copyright holder for this preprint (which was not certified by peer review) is the author/funder, who has granted medRxiv a license to display the preprint in perpetuity. It is made available under a CC-BY-ND 4.0 International license .

in Africa and Europe emphasizing regional connectedness and land-based travel as drivers of viral transmission. . $^{2,7,7}$

Our findings emphasize that strategies aiming to stop or slow the spread of viral introductions (including new variants) with travel restrictions need to prioritize managing risk from land-based travel including commercial transport alongside intercontinental air travel for restrictions to be effective. ${ }^{26}$ Jordan's land crossings were only open for commercial cargo from March 2020 until late October 2020. ${ }^{27}$ The Jordanian government has been responsive to the high number of infections associated with truck drivers. Jordan first mandated routine testing and institutional quarantine upon arrival at the border for all truck drivers on 15 April 2020 after infections were reported in truck drivers returning from Saudi Arabia and their contacts. ${ }^{28,29}$ However, early cases and superspreading events were continuously associated with truck drivers, particularly crossing from Saudi Arabia. ${ }^{29-34}$ The early preventative measures were likely undermined by overcrowding at the border crossings, initial self-reported quarantining, and delays in construction of the quarantine site at the Al-Omari border with Saudi Arabia, though unloading methods were adapted to minimize contact between drivers. ${ }^{35-37}$ The government responsively closed the NasibJaber crossing connecting Jordan to Syria and the wider region in mid-August, which was associated with an increase in cases in border officials and truck drivers concurrent to a surge in cases in Syria. ${ }^{38-40}$ Future and current containment strategies that rely on travel restrictions may benefit from targeting truck drivers for free rapid antigen testing programs at scale. ${ }^{41}$

We did not identify many transmissions from Jordan to other Middle Eastern countries, though our exportation intensity index suggests continuous and relatively high export risk. This underestimation highlights how undersampling an entire region can obscure the importance of regional connectedness in sustaining local epidemics. ${ }^{5-7}$ The temporal trend of the introduction risk profile was robust to our downsampling strategies and randomizations. However, datasets with higher representation from Middle Eastern countries did have higher estimated introductions from the Middle East. This expected effect of downsampling strategy and randomization on source-sink dynamics emphasizes the need for caution in inference with a rapidly, globally dispersing pathogen subject to intense but biased sampling. . $^{1,6,42}$

Our results should be interpreted in the context of our limited sampling, which represented $0.11 \%$ of all observed cases and was disproportionate to epidemic incidence with temporal gaps. Our introduction estimates are likely severely underestimated, given our small sample size and the negligible likelihood of observing singleton introductions or small-scale transmission chains. ${ }^{2}$ Our land and air travel data was aggregated by month, and we assumed travel was uniform across the month to calculate a daily introduction and exportation intensity. The introduction intensity index (II) quantifies the temporal trend in the daily estimated number of introductions rather than absolute values as it is based on the back-extrapolated time series of deaths and is therefore restricted by the associated reporting delays and biases. Notably, the II will be severely underestimated for countries such as Syria and Yemen with large-scale case and death underascertainment. ${ }^{43}$ Our counterfactual II for the travel restriction period assumed travel patterns for March to September are similar to January and February, which are potentially inflated by holiday travel patterns. It also does not consider restrictions applied by the origin of 
medRxiv preprint doi: https://doi.org/10.1101/2022.01.27.22269922; this version posted January 28, 2022. The copyright holder for this preprint (which was not certified by peer review) is the author/funder, who has granted medRxiv a license to display the preprint in perpetuity. It is made available under a CC-BY-ND 4.0 International license .

return-travel passengers, which would likely have disincentivized travel and reduced volumes overall.

It is clear that surveillance infrastructure in Jordan and the wider Middle East is insufficient to characterize the transmission dynamics of SARS-CoV-2, including monitoring of new variants of concern. We detected the first cases of the highly transmissible B.1.617.2 Delta variant in Jordan on 26 April 2021, after which it replaced the B.1.1.7 Alpha variant based on the sharp decline in the percentage SGTF observed. However, there was limited sequencing to confirm this. We also detected the first Omicron variant on 7 December 2021, with limited sequencing capacity to monitor its transmission dynamics.

Considering the strong connectedness evidenced in this work, it is important that regional surveillance programs coordinate and pool resources to strengthen regional capacity. Recent modeling has provided tools for calculating the level of sequencing required to detect emerging variants at different frequencies. ${ }^{44}$ The framework suggests that surveillance programs would need to sequence 300 representative cases to detect at least one genome of a lineage, e.g. a new variant of concern, with a frequency of $2 \%$ in the population with $95 \%$ probability. This framework suggests that at least $0.5 \%$ of cases should be sequenced with rapid turnaround $(<3$ weeks) during periods of high incidence to improve local and global capacity to detect new variants as they emerge. Current sampling efforts in Jordan, with a sampling fraction of $0.11 \%$ across 2020 and a largely unsequenced second wave in 2021, as well as the wider Middle East fall far short of this goal.

As an international community, we need to invest in more equitably distributed, locally sustained genomic surveillance infrastructure as well as diagnostic and human capacity that can function and scale in real-time, without the delays associated with dependence of low- and middle-income countries or Global South institutions on others. There are significant inequities in public financing, the social determinants of health and health system capacity across the Middle East. ${ }^{45}$ Public health efforts in several Middle Eastern countries, including Syria, Yemen and Palestine have had to operate under conditions of conflict, displacement and extreme resource and infrastructure limitations, with large vulnerable populations of refugees in other Middle Eastern countries. ${ }^{46,47}$ Systematically and sustainably strengthening surveillance and diagnostic capacity across the Middle East and other regions worldwide is not only imperative to empower local public health decision making, but is also vital to monitor and pre-empt the global spread of new variants of concern as well as other emerging zoonosis in real-time in a vulnerably connected world. 


\section{Acknowledgments}

We would like to acknowledge Mohammad Ghneim from Biolab's IT department for data extraction from LIMS, Fares Abu-Dayyeh from Jordan's Ministry of transport, Imad Ghuwairi from Jordan customs, and Daoud Sawaeer for facilitating the attainment of land travel data. We thank Diala Haddadin for collecting the raw data for the timeline of non-pharmaceutical public health interventions, Yuxia Bo and Justin Whitaker for technical help, and Vera A. Tang from the University of Ottawa Flow Cytometry and Virometry Core Facility for technical support. We thank the administrators of the GISAID database for supporting rapid and transparent sharing of genomic data during the COVID-19 pandemic and all our colleagues sharing data on GISAID. A full list acknowledging the authors submitting genome sequence data used in this study can be found in Supplementary table 3. This work has been funded by CDC BAA contracts 75D30120C09795 (K.G.A.), NIH NIAID 3U19AI135995-03S2 ( K.G.A.), U19AI135995 (K.G.A.), U01AI151812 (K.G.A.), NIH NCATS UL1TR002550 (K.G.A.), NIH NIAID R01 Al135992 (J.O.W).. This research was supported by the National Institute of Allergy and Infectious Diseases of the National Institutes of Health under Award Numbers 1U01Al151378-01 (subaward Number 8-312-0217530-66439L). Experimental part conducted by Marceline Côté's laboratory was supported by a COVID-19 Rapid Research grant from the Canadian Institutes for Health Research (OV3 170632) to M.C. M.C. is a Canada Research Chair in Molecular Virology and Antiviral Therapeutics and a recipient of an Ontario Early Researcher Award. 
medRxiv preprint doi: https://doi.org/10.1101/2022.01.27.22269922; this version posted January 28, 2022. The copyright holder for this preprint (which was not certified by peer review) is the author/funder, who has granted medRxiv a license to display the preprint in perpetuity.

It is made available under a CC-BY-ND 4.0 International license .

\section{Methods}

\section{Ethical Clearance}

The study was approved by the Institutional Review Boards (IRBs) at Scripps Research Institute (TSRI) (IRB-21-7739) and the Cell Therapy Center of The University of Jordan (IRD-CTC/12020/01)

\section{Sample collection}

We collected SARS-CoV2 samples from routine diagnostic tests performed by Biolab Diagnostic Laboratories, which has 20 branches in five governorates including major cities Amman, Irbid, and Zarqa. We collated samples from walk-in/drive-through testing centers, public and private referral laboratories, house-call services as well as health care facilities. We sequenced samples predominantly from the densely populated Amman (population $>4$ million) and Irbid (population $>2$ million), which were also the epicenters of the outbreak in Jordan across both waves in our study period. Five to ten percent of total samples with a Ct value $<32$ in the TaqPath COVID-19 PCR assay were selected at random for sequencing across the major cities. Screening for variants of concern (VOC) by S-gene target failure (SGTF) and mutation-specific primer sets was implemented from late December 2020. Samples where all three target regions of the ORF-1, S, and $\mathrm{N}$ genes were amplified were deemed non-SGTFs, while those where ORF-1 and N gene target regions were amplified only, were classified as SGTFs and used subsequently for random sample selection for sequencing. In total, we generated 579 sequences before variant screening and 37 Alpha variant sequences during the period of this study.

\section{SARS-CoV-2 whole-genome sequencing}

SARS-CoV-2 was sequenced using PrimalSeq-Nextera XT. This protocol is based on the ARTIC PrimalSeq protocol and adapted for Illumina Nextera XT library preparation. ${ }^{48}$ The ARTIC network nCoV-2019 V3 primer scheme uses two multiplexed primer pools to create overlapping $400 \mathrm{bp}$ amplicon fragments in two PCR reactions. Instead of ligating Illumina adapters, Nextera XT is used to circumvent the $2 \times 250$ or $2 \times 300$ read length requirement. A detailed version of this protocol can be found here: https://andersen-lab.com/secrets/protocols/. Briefly, SARS-CoV-2 RNA (2 mL) was reverse transcribed with SuperScript IV VILO (ThermoFisher Scientific). The virus cDNA was amplified in two multiplexed PCR reactions (one reaction per ARTIC network primer pool) using Q5 DNA High-fidelity Polymerase (New England Biolabs). Following an AMPureXP bead (Beckman Coulter) purification of the combined PCR products, the amplicons were diluted, and libraries were prepared using Nextera XT (Illumina) or NEBNext Ultra II DNA Library Prep Kits (New England Biolabs). The libraries were purified with AMPureXP beads and quantified using the Qubit High Sensitivity DNA assay kit (Invitrogen) and Tapestation D5000 tape (Agilent). The individual libraries were normalized and pooled in equimolar amounts at $2 \mathrm{nM}$. The $2 \mathrm{nM}$ library pool was sequenced on an Illumina NextSeq using a 500/550 Mid Output Kit v2.5 (300 Cycles). A subset of samples from Ochsner Health were processed without tagmentation and sequenced 
medRxiv preprint doi: https://doi.org/10.1101/2022.01.27.22269922; this version posted January 28, 2022. The copyright holder for this preprint (which was not certified by peer review) is the author/funder, who has granted medRxiv a license to display the preprint in perpetuity.

It is made available under a CC-BY-ND 4.0 International license .

on a Illumina MiSeq using a MiSeq reagent kit V3 (600 cycles). Consensus sequences were assembled using an inhouse Snakemake ${ }^{49}$ pipeline with bwa-mem ${ }^{50}$ and iVar v1.2.2 ${ }^{51}$.

\section{Downsampling strategies and dataset curation}

Phylogeographic inferences are fundamentally dependent on and confounded by sampling biases and downsampling strategy. Models that explicitly incorporate travel history and unsampled lineages from undersampled populations are required to account for the rapid rate of viral dispersal and uneven sampling between locations that may result in unsampled intermediary locations. ${ }^{6,42}$ However, we did not have access to the travel histories of our sequences. We therefore assessed the robustness of our findings over three random replicates of three downsampling strategies developed to minimize the impact of sampling biases in a computationally tractable dataset $(n=1500, n=921$ background sequences in combination with $\mathrm{n}=579$ Jordanian sequences).

The downsampling strategies are:

1. Epidemiological incidence informed (EII). Sequences were randomly subsampled proportional to country-specific incidence data binned by epidemiological week to maintain a realistic sampling time distribution and to attempt to make the number of sequences from each country proportional to the country's incidence for phylogeographic reconstruction. We obtained the time series of reported cases for all available countries using the outbreak.info $R$ package, which aggregates epidemiological data from the COVID-19 data repository by the Center for Systems Science and Engineering (CSSE) at Johns Hopkins University. ${ }^{52,53}$

2. The regional enrichment (RE) dataset corrected the subsampling probabilities of the EII dataset, increasing the sampling weights of countries from the Middle East or MENA region by a factor of five. The Middle East and North Africa region was defined as Algeria, Bahrain, Egypt, Iran, Iraq, Israel, Jordan, Kuwait, Lebanon, Libya, Morocco, Oman, Palestine, Qatar, Saudi Arabia, Syria, Tunisia, United Arab Emirates, Yemen and included Turkey.

3. The introduction Intensity Index informed (III) dataset. Sequences were randomly downsampled by country and epiweek with inclusion probabilities based on the estimated II (introduction intensity) (see section below). This approach maximizes the inclusion of sequences from source countries according to their relative risk of introduction to Jordan, assuming our land and air travel data represents a highly accurate picture of in-bound traffic.

We selected sequences according to the downsampling strategies from all publicly available sequences in GISAID for the period up to 31 March 2021 after filtering out duplicates, sequences without complete sampling dates and sequences with $>5 \%$ ambiguous nucleotides. Three random replicate datasets were generated for each downsampling strategy. GISAID IDs and author acknowledgements are provided in Supplementary table 3. Additionally, we reconstructed lineage-specific builds for B.1.1.312 and B.1.36.10 (the two major circulating clades in Jordan's first wave) and B.1.1.7 (which drove Jordan's second wave) to ensure inclusion of all relevant 
medRxiv preprint doi: https://doi.org/10.1101/2022.01.27.22269922; this version posted January 28, 2022. The copyright holder for this preprint (which was not certified by peer review) is the author/funder, who has granted medRxiv a license to display the preprint in perpetuity.

It is made available under a CC-BY-ND 4.0 International license .

sequences in more tractable datasets. We included all publicly available B.1.1.312 after filtering as above $(n=474)$ and B.1.36.10 $(n=155)$ sequences on GISAID in their respective datasets. For the B.1.1.7 dataset, we followed the Ell downsampling approach set out above to generate three random replicates of $n=500$.

\section{Phylogenetic analyses}

We aligned the sequence datasets to the reference genome Wuhan-Hu-1 (GenBank: MN908947.3) using MAFFTv7. ${ }^{54}$ We masked the 5' and 3' UTRs as well as sites previously identified as potential sequencing errors or suspect homoplasies. ${ }^{55}$ We reconstructed maximum likelihood phylogenetic trees for each dataset using IQTREE2 under ModelFinder. ${ }^{56,57}$ We collapsed zero branch lengths to account for the large number of polytomies that characterize SARS-CoV-2 phylogenies. We explored temporal structure in our dataset across fixed (root MN908947.3) and optimized rooting strategies using temporal regression in TreeTime 0.8.3, excluding outlying sequences more than three interquartile ranges from the clock filter. ${ }^{58}$

We assigned lineages to each sequence set with the Pangolin nomenclature tool (version 3.1.11). ${ }^{18}$ Lineage dissimilarity between countries was quantified as the Bray-Curtis distance between pairwise presence-absence matrices of lineage counts binned by epidemiological week using the vegan package in R. ${ }^{59}$

We reconstructed time-scaled phylogenies for each dataset using BEAST 1.10.5. ${ }^{60}$ We used the HKY substitution model with a gamma-distributed rate variation among sites across all of the global datasets. ${ }^{61}$ We used a strict clock in the global datasets, with an informative lognormal prior and an exponential growth coalescent tree prior. We used an uncorrelated relaxed clock model with a lognormal prior in the smaller lineage-specific datasets. For each of the nine global datasets (non-lineage specific builds), we combined two independent MCMC chains of 200 million states ran with the BEAGLE computational library ${ }^{60}$ Parameters and trees were sampled every 20000 steps, with the first $20 \%$ of steps discarded as burn-in. For the lineage-specific datasets, we combined two independent chains of 100 million states, sampled every 10000 steps with a burnin of $10 \%$. Convergence and mixing of the MCMC chains were assessed in Tracer v1.7, to ensure the effective sample size (ESS) of all estimated parameters were $>200 .^{62}$

We performed an asymmetric discrete trait analysis in BEAST version 1.10 .5 with geographic states aggregated on a regional level to reconstruct the location-transition history across an empirical distribution of 4000 time-calibrated trees sampled from each of the posterior tree distributions estimated above. ${ }^{63}$ Country-level traits were used for increased location history resolution for the more computationally tractable B.1.1.312 and B.1.36.10 lineage-specific datasets. We used Bayesian stochastic search variable selection (BSSVS) to infer non-zero migration rates and identify the statistically supported transition routes into and out of Jordan by a Bayes Factor test. ${ }^{63}$

Biases from unrepresentative sampling are compounded by uncertainty in the phylogenetic structure. SARS-CoV-2 phylogenies are often poorly supported by the posterior distribution owing to the low diversity in the sequence data, with poorly resolved regions (especially large 
medRxiv preprint doi: https://doi.org/10.1101/2022.01.27.22269922; this version posted January 28, 2022. The copyright holder for this preprint (which was not certified by peer review) is the author/funder, who has granted medRxiv a license to display the preprint in perpetuity.

It is made available under a CC-BY-ND 4.0 International license .

polytomies) limiting robust reconstruction of evolutionary and phylogeographic relationships. ${ }^{1} \mathrm{We}$ included a Markov jump counting procedure to investigate the timing and origin of geographic transitions, or Markov jumps, into Jordan across the full posterior to account for uncertainty in phylogeographic reconstruction associated with sparse sampling and low sequence variability. ${ }^{17}$ We used the TreeMarkovJumpHistoryAnalyzer from the pre-release version of BEAST 1.10.5 to obtain the Markov jumps and their timings from posterior tree distributions. ${ }^{7} \mathrm{We}$ used TreeAnnotator 1.10 to construct Maximum clade credibility (MCC) trees for all datasets. Trees were visualized using baltic (https://github.com/evogytis/baltic).

\section{Epidemiological data and estimation of effective reproduction number}

We estimated the time-varying effective reproduction number with the Epinow2 package, fitting the time series of cases using Markov-chain Monte Carlo (MCMC) sampling, with 4 chains of 4000 samples and a warm-up of 1000 . We obtained the time series of reported cases for Jordan using the outbreak.info $\mathrm{R}$ package ${ }^{52}$ We assumed the same generation and reporting delayed distributions as ${ }^{64}$ and assessed posterior convergence using the Rhat statistic. We only modeled the $R(t)$ from the 3rd of July onwards - after the occurrence of the first 10 deaths - as this is the period when local transmission not introduction was assumed to be the dominant source of new infections. $^{65}$

\section{Data sources and timeline of interventions}

We collated data on the timing and type of all major non-pharmaceutical interventions in Jordan for the entire study period. Data sources on the laws and measures executed included the official communications of the government of Jordan, including its Ministry of Health, as well as major media sources (See Supplementary table 2 for the full timeline and reference sources). Major interventions of interest included comprehensive and stringent nighttime curfews, public event bans, gathering restrictions, school closures, workplace closures, mandatory mask wearing policies and the closure of specific economic sectors. The intervention timeline from primary sources was validated against the timeline from the Oxford Covid-19 Government Response Tracker (OxCGRT), with interventions conservatively considered to be in place if coded as "required" not "recommended". ${ }^{66}$ Conflicts were resolved using the primary sources.

\section{Travel and mobility data}

We collated several independent data sources to understand Jordan's mobility and connectivity over time. We obtained air passenger volumes aggregated by month from the International Air Transportation Association (IATA) for January to December 2020. This dataset included the number of incoming and outgoing passengers by origin/destination country to/from Jordan's two international airports, the Queen Alia International Airport in Amman and the King Hussein International Airport in Aqaba. Land-based travel volumes were obtained from the Customs 
medRxiv preprint doi: https://doi.org/10.1101/2022.01.27.22269922; this version posted January 28, 2022. The copyright holder for this preprint (which was not certified by peer review) is the author/funder, who has granted medRxiv a license to display the preprint in perpetuity.

It is made available under a CC-BY-ND 4.0 International license .

Agency of the Hashemite Kingdom of Jordan via direct communication. This data included the number of private vehicles, buses and trucks entering and exiting Jordan aggregated by month. Jordan's borders include crossings from Syria (Jaber, Ramtha crossing), Iraq (Al-Karamah Border Crossing), Israel and Palestine (Allenby/King Hussein Bridge, Sheikh Hussein crossing , Wadi Araba Crossing) and Saudi Arabia (Umari Border Crossing, Mudawara Border Crossing, Durra Border Crossing) and passenger ferries from Egypt. As there was no information on the complete route, vehicles were assumed to have originated only from the country of the crossing. For vehicles without an assigned origin, the nationality of the passengers was assigned if from the MENA region.

\section{Estimated introduction and exportation intensity index}

We follow Du Plesis et al. ${ }^{2}$ in calculating the introduction intensity index (II). Briefly, the II estimates the daily risk of introductions into Jordan from each source country as the product of the number of asymptomatically infectious individuals in each source country on that day (based on backextrapolated death time series) and their likelihood to travel to Jordan based on the volume of inbound land and air travel from the source country. We assumed the same estimates for the latent and incubation period, infectious duration, symptom-onset-to-death and asymptomatic proportion as Du Plesis et $\mathrm{al}^{2}$ (See ${ }^{2}$ for full details). We obtained the time series of reported deaths from each country from the outbreak.info $\mathrm{R}$ package. To model incoming travel in the II, we combine the air and land-based volumes for each source country as applicable. Both the land and air travel data were aggregated by month. In the absence of additional information, we assumed that travel was uniform across all days in the month. The land-based travel dataset did not include the number of passengers in each car, bus or truck. We conservatively assume one passenger per truck, 1.5 passengers per car and 10 passengers per bus to quantify the number of inbound and outbound land-based passengers for the II. The II was quantified for January 2020 - December 2020. We did not consider traffic at Jordan's maritime border, which would underestimate Jordan's connectivity to Egypt. The export intensity index was qualified under the same assumptions for outgoing travel, integrated with Jordan's epidemiological curve. We examined the sensitivity of our II and EII results to the fixed parameters (asymptomatic proportion (ranging 0.2-0.5), generation time (4-10 days)). Our results were robust over these ranges (not shown). We also performed sensitivity analyses of the assumed number of people per car or bus for land travel, fixing truck passengers at 1 per truck. However, results were robust to ranging passengers in buses (10-40) and cars (1-4) as land travel was predominantly driven by truck volume.

\section{Adaptive evolution of the Q957L substitution}

We investigate the possibility that the Q957L substitution of the B.1.1.312 lineage resulted from diversifying positive selection using the MEME (Mixed Effects Model of Evolution) model in Hyphy v2.5.27. ${ }^{67,68}$ 


\section{Structural analyses of the Q957L substitution}

We used FoldX to estimate the structural stability effects of Q957L in the heptad repeat region of the S2 spike subunit. The spike protein structure (PDB: 7DWY) was first repaired by removing potential steric clashes. ${ }^{69}$ The difference in free energy changes arising from Q957L was then estimated under default parameters (298K, ionic strength of $0.05 \mathrm{M}$ and $\mathrm{pH} 7.0$ ) using FoldX's empirical force field model which has a reported standard deviation of $0.46 \mathrm{kcal} / \mathrm{mol}$ between computed and experimentally measured values. ${ }^{70}$ The mutation analysis was repeated five times and the mean and standard deviation free energy change values were reported.

\section{Experimental characterization of the Q957L substitution}

Cells and Plasmids

HEK293T (ATCC) and Calu-3 (ATCC) were cultured in Dulbecco's Modified Eagle Media (DMEM) supplemented with $10 \%$ Fetal Bovine Serum (FBS) and pen/strep/glut and maintained at $37^{\circ} \mathrm{C}$ at $100 \%$ relative humidity.

The ancestral (WT) SARS-CoV-2 S cDNA was codon-optimized (GeneArt, ThermoFisher), synthesized as gene blocks (BioBasics), assembled by overlapping PCR, and cloned in pCAGGS. The Q957L mutation was introduced by overlapping PCR in the WT S or S bearing the D614G, also introduced by overlapping PCR. All $S$ gene constructs were fully sequenced by Sanger sequencing.

Lentiviral pseudotypes and transduction

HEK293T cells were co-transfected with psPAX2 (gift from Didier 99 Trono, Addgene plasmid\#12260), pLV-eGFP (gift from Pantelis Tsoulfas, Addgene plasmid \# 36083) and plasmids encoding SARS CoV-2 S D614G, D614G and Q957L, or empty pCAGGS (mock) using JetPrime (Polyplus transfection, France) following the manufacturer's protocol. Twenty-four hours posttransfection, the medium was changed with DMEM $2 \%$ FBS pen/strep/glut. Media containing lentiviral particles were harvested at 48- and 72-hours post-transfection. The viral producer cells were then washed with cold PBS and lysed (1\%Triton X-100, 0.1\% Igepal, 150mM NaCl, 50mM Tris- $\mathrm{HCl}, \mathrm{pH} 7.5,1 \mathrm{X}$ protease inhibitor cocktail (Cell Signaling)) on ice. Lysates were pre-cleared by centrifugation and proteins were denatured and resolved by SDS-PAGE. Proteins were then transferred onto PVDF membranes and S2 and GAPDH were detected by immunoblotting.

Media were filtered using $0.45 \mu \mathrm{m}$ filters and directly used to transduce Calu- 3 in the presence of $5 \mu \mathrm{g} / \mathrm{mL}$ polybrene. Forty-eight hours post-transduction, Calu-3 were trypsinized and resuspended in PBS-2\% for flow cytometry analysis. The percentage of transduced cells was quantitated by measuring the GFP+ cells. 
Cell-cell fusion assay

The bi-molecular fluorescence complementation (BiFC) has been described previously* . Briefly, the HEK293T target cells were transfected using Jetprime with plasmids encoding the GCN4 leucine zipper-Venus1 (ZipV1, kind gift of Stephen W. Michnick, McGill University*), Ace2myc (pCEP4-myc-ACE2 was a gift from Erik Procko (Addgene plasmid \# 141185) ${ }^{*}$ and TMPRSS2 (from MISSION TRC3 Human LentiORF Puormycin Library, MilliporeSigma). The HEK293T effector cells were transfected using Jetprime with plasmid encoding GCN4 leucine zipperVenus2 (ZipV2, also from Stephen W. Michnick) and pCAGGS encoding SARS-CoV-2 S WT, Q957L, or pCAGGS vector. Twenty-four hours post-transfection, cells were washed with PBS and detached with versene (PBS, 0.53mM EDTA) and resuspended in serum- and phenol red-free DMEM. Wells of a 384-well black plates with optical clear bottom were seeded with effector and target cells (35,000 cells of each population per well) and incubated for 3 hours at $37^{\circ} \mathrm{C}, 5 \% \mathrm{CO} 2$. BiFC signal was acquired using Biotek Synergy Neo2 plate reader (BioTek Instruments) using monochromator set to excitation/emission of 500 and $542 \mathrm{~nm}$.

\section{Data sharing and code availability}

The raw data and code for our analyses can be found at https://github.com/andersenlab/paper 2022 jordan-sars2-phylogenetics. 
1. Worobey, M. et al. The emergence of SARS-CoV-2 in Europe and North America. Science 370, 564-570 (2020).

2. du Plessis, L. et al. Establishment and lineage dynamics of the SARS-CoV-2 epidemic in the UK.

3. Washington, N. L. et al. Emergence and rapid transmission of SARS-CoV-2 B.1.1.7 in the United States. Cell 184, 2587-2594.e7 (2021).

4. Tegally, H. et al. Sixteen novel lineages of SARS-CoV-2 in South Africa. Nat. Med. 27, 440-446 (2021).

5. Butera, Y. et al. Genomic sequencing of SARS-CoV-2 in Rwanda reveals the importance of incoming travelers on lineage diversity. Nat. Commun. 12, 1-11 (2021).

6. Dudas, G. et al. Emergence and spread of SARS-CoV-2 lineage B.1.620 with variant of concern-like mutations and deletions. Nat. Commun. 12, 1-12 (2021).

7. Lemey, P. et al. Untangling introductions and persistence in COVID-19 resurgence in Europe. Nature 595, 713-717 (2021).

8. Hodcroft, E. B. et al. Spread of a SARS-CoV-2 variant through Europe in the summer of 2020. Nature 595, 707-712 (2021).

9. 2,028 people quarantined in the Dead Sea hotels, 2,995 in Amman hotels. https://en.royanews.tv/news/20279/2020-03-17.

10. Miller, D. et al. Full genome viral sequences inform patterns of SARS-CoV-2 spread into and within Israel. Nat. Commun. 11, 5518 (2020).

11. Qutob, N. et al. Genomic epidemiology of the first epidemic wave of severe acute respiratory syndrome coronavirus 2 (SARS-CoV-2) in Palestine. Microb Genom 7 , 
(2021).

12. Omais, S., Kharroubi, S. \& Zaraket, H. No association between the SARS-CoV-2 variants and mortality rates in the Eastern Mediterranean Region. bioRxiv (2021) doi:10.1101/2021.01.06.21249332.

13. Al-Mahruqi, S. et al. Molecular epidemiology of COVID-19 in Oman: A molecular and surveillance study for the early transmission of COVID-19 in the country. Int. J. Infect. Dis. 104, 139-149 (2021).

14. Sallam, M., Ababneh, N. A., Dababseh, D., Bakri, F. G. \& Mahafzah, A. Temporal increase in D614G mutation of SARS-CoV-2 in the Middle East and North Africa. Heliyon 7, e06035 (2021).

15. Tayoun, A. A. et al. Multiple early introductions of SARS-CoV-2 into a global travel hub in the Middle East. Sci. Rep. 10, 17720 (2020).

16. Ghafari, M., Karlinsky, A., Watson, O. J., Ferretti, L. \& Katzourakis, A. Detailed reconstruction of the Iranian COVID-19 epidemic reveals high attack rates of SARS-CoV-2 in several provinces. bioRxiv (2021) doi:10.1101/2021.10.04.21264540.

17. Minin, V. N. \& Suchard, M. A. Counting labeled transitions in continuous-time Markov models of evolution. J. Math. Biol. 56, 391-412 (2008).

18. O'Toole, Á. et al. Assignment of epidemiological lineages in an emerging pandemic using the pangolin tool. Virus Evol 7, veab064 (2021).

19. Volz, E. et al. Evaluating the Effects of SARS-CoV-2 Spike Mutation D614G on Transmissibility and Pathogenicity. Cell 184, 64-75.e11 (2021).

20. Liu, S. et al. Interaction between heptad repeat 1 and 2 regions in spike protein of 
SARS-associated coronavirus: implications for virus fusogenic mechanism and identification of fusion inhibitors. Lancet 363, 938-947 (2004).

21. Hajjo, R., Sabbah, D. A. \& Bardaweel, S. K. Emerging SARS-CoV-2 lineages in middle eastern Jordan with increasing mutations near antibody recognition sites. bioRxiv (2021) doi:10.1101/2021.02.09.21251052.

22. Sallam, M. \& Mahafzah, A. Molecular Analysis of SARS-CoV-2 Genetic Lineages in Jordan: Tracking the Introduction and Spread of COVID-19 UK Variant of Concern at a Country Level. Pathogens 10, (2021).

23. Health Alert: Three Border Crossings to Open with Limited Capacity (October 28, 2020). https://jo.usembassy.gov/health-alert-three-border-crossings-to-open-withlimited-capacity-october-28-2020/.

24. Kraemer, M. U. G. et al. Spatiotemporal invasion dynamics of SARS-CoV-2 lineage B.1.1.7 emergence. Science 373, 889-895 (2021).

25. Davis, J. T. et al. Cryptic transmission of SARS-CoV-2 and the first COVID-19 wave in Europe and the United States. medRxiv (2021) doi:10.1101/2021.03.24.21254199.

26. Grépin, K. A. et al. Evidence of the effectiveness of travel-related measures during the early phase of the COVID-19 pandemic: a rapid systematic review. BMJ Glob Health 6, (2021).

27. COVID-19: Jordan reopens three land border crossings. https://gulfnews.com/world/mena/covid-19-jordan-reopens-three-land-bordercrossings- 1.74835141 .

28. Zero COVID-19 test fees for Jordanian truck drivers - says PM. 
https://www.petra.gov.jo/Include/InnerPage.jsp?ID=27005\&lang=ar\&name=en_new

$s$.

29. 3 truck drivers test positive for COVID-19 at border; no new infections confirmed within Kingdom. https://www.jordantimes.com/news/local/3-truck-drivers-testpositive-covid-19-border-no-new-infections-confirmed-within-kingdom.

30. Jordan reports 38 COVID-19 cases over weekend, as lockdown lifted. https://www.jpost.com/middle-east/jordan-reports-38-covid-19-cases-overweekend-as-lockdown-lifted-627501.

31. Jordan Records 'Zero' Covid-19 Cases But 8 Truck Drivers With Virus on Eastern Border. https://www. albawaba.com/news/jordan-records-zero-covid-19-cases-8truck-drivers-virus-kingdoms-eastern-border-1351983.

32. For the second day in a row, no corona cases recorded in Jordan, 3 reported at borders. https://en.royanews.tv/news/20789/2020-04-21.

33. Inspection teams start testing people who had direct contact with infected driver in Mafraq. https://en.royanews.tv/news/20945/2020-05-07.

34. Health Minister: 24 new coronavirus cases recorded in Jordan today. https://en.royanews.tv/news/20963/2020-05-08.

35. Truck Owners Syndicate calls for easing COVID restrictions at Iraqi border. https://www.jordantimes.com/news/local/truck-owners-syndicate-calls-easing-covidrestrictions-iraqi-border (2021).

36. Jordanian truck drivers arriving at borders to be quarantined temporarily in military schools. https://en.royanews.tv/news/20964/Jordanian-Truck-Drivers-Arriving-atBorders-to-Be-Quarantined-Temporarily-in-Military-Schools. n.d. 'Jordanian Truck 
Drivers Arriving at Borders to Be Quarantined Temporarily in Military Schools.'

37. BORDER DROP-OFF YARD AND QUARANTINE CAMPS TO BE COMPLETED BEFORE END OF MAY. http://jordanembassyus.org/news/border-drop-yard-andquarantine-camps-be-completed-end-may.

38. Al-Khalidi, S. Jordan reopens trade gateway with Syria after month-long COVID closure. https://www.reuters.com/article/us-health-coronavirus-jordan-syria/jordanreopens-trade-gateway-with-syria-after-month-long-covid-closureidUSKBN26IOW5.

39. Coronavirus: Jordan to close border with Syria after spike in COVID-19 cases. https://english.alarabiya.net/coronavirus/2020/08/12/Coronavirus-Jordan-to-closeborder-with-Syria-after-spike-in-COVID-19-cases.

40. Jaber Border Crossing into Syria closes from Thursday. https://en.royanews.tv/news/21817/2020-08-12.

41. Mina, M. J. \& Andersen, K. G. COVID-19 testing: One size does not fit all. Science 371, 126-127 (2021).

42. Lemey, P. et al. Accommodating individual travel history and unsampled diversity in Bayesian phylogeographic inference of SARS-CoV-2. Nat. Commun. 11, 5110 (2020).

43. Van Elsland, S. et al. Report 31: Estimating the burden of COVID-19 in Damascus, Syria: an analysis of novel data sources to infer mortality under-ascertainment. http://spiral.imperial.ac.uk/handle/10044/1/82443 (2020) doi:10.25561/82443.

44. Brito, A. F. et al. Global disparities in SARS-CoV-2 genomic surveillance. medRxiv (2021) doi:10.1101/2021.08.21.21262393. 
45. Rekha, D. D. M. Mitigating the Impact of COVID-19 and Strengthening Health Systems in the Middle East and North Africa. https://openknowledge.worldbank.org/handle/10986/34238 (2020).

46. Karamouzian, M. \& Madani, N. COVID-19 response in the Middle East and north Africa: challenges and paths forward. Lancet Glob Health 8, e886-e887 (2020).

47. McNatt, Z. Z. Addressing noncommunicable diseases among urban refugees in the Middle East and North Africa - a scoping review. Confl. Health 14, 9 (2020).

48. Quick, J. et al. Multiplex PCR method for MinION and Illumina sequencing of Zika and other virus genomes directly from clinical samples. Nat. Protoc. 12, 1261-1276 (2017).

49. Köster, J. \& Rahmann, S. Snakemake-a scalable bioinformatics workflow engine. Bioinformatics 28, 2520-2522 (2012).

50. Li, H. Aligning sequence reads, clone sequences and assembly contigs with BWAMEM. arXiv [q-bio.GN] (2013).

51. Grubaugh, N. D. et al. An amplicon-based sequencing framework for accurately measuring intrahost virus diversity using PrimalSeq and iVar. Genome Biol. 20, 8 (2019).

52. R-outbreak.info. https://github.com/outbreak-info/R-outbreak-info (2020).

53. Dong, E., Du, H. \& Gardner, L. An interactive web-based dashboard to track COVID-19 in real time. Lancet Infect. Dis. 20, 533-534 (2020).

54. Katoh, K. \& Standley, D. M. MAFFT multiple sequence alignment software version 7: improvements in performance and usability. Mol. Biol. Evol. 30, 772-780 (2013). 55. Issues with SARS-CoV-2 sequencing data. https://virological.org/t/issues-with-sars- 
cov-2-sequencing-data/473 (2020).

56. Minh, B. Q. et al. IQ-TREE 2: New Models and Efficient Methods for Phylogenetic Inference in the Genomic Era. Mol. Biol. Evol. 37, 1530-1534 (2020).

57. Kalyaanamoorthy, S., Minh, B. Q., Wong, T. K. F., von Haeseler, A. \& Jermiin, L. S. ModelFinder: fast model selection for accurate phylogenetic estimates. Nat. Methods 14, 587-589 (2017).

58. Sagulenko, P., Puller, V. \& Neher, R. A. TreeTime: Maximum likelihood phylodynamic analysis. Virus Evol 4, vex042 (2018).

59. Oksanen, J. et al. Vegan: community ecology package. (2019).

60. Suchard, M. A. et al. Bayesian phylogenetic and phylodynamic data integration using BEAST 1.10. Virus Evol 4, vey016 (2018).

61. Hasegawa, M., Kishino, H. \& Yano, T. Dating of the human-ape splitting by a molecular clock of mitochondrial DNA. J. Mol. Evol. 22, 160-174 (1985).

62. Rambaut, A., Drummond, A. J., Xie, D., Baele, G. \& Suchard, M. A. Posterior Summarization in Bayesian Phylogenetics Using Tracer 1.7. Syst. Biol. 67, 901904 (2018).

63. Lemey, P., Rambaut, A., Drummond, A. J. \& Suchard, M. A. Bayesian phylogeography finds its roots. PLoS Comput. Biol. 5, e1000520 (2009).

64. Abbott, S. et al. Estimating the time-varying reproduction number of SARS-CoV-2 using national and subnational case counts. Wellcome Open Research 5, 112 (2020).

65. Flaxman, S. et al. Estimating the effects of non-pharmaceutical interventions on COVID-19 in Europe. Nature 584, 257-261 (2020). 
66. Hale, T. et al. A global panel database of pandemic policies (Oxford COVID-19 Government Response Tracker). Nat Hum Behav 5, 529-538 (2021).

67. Murrell, B. et al. Detecting individual sites subject to episodic diversifying selection. PLoS Genet. 8, e1002764 (2012).

68. Kosakovsky Pond, S. L. et al. HyPhy 2.5-A Customizable Platform for Evolutionary Hypothesis Testing Using Phylogenies. Mol. Biol. Evol. 37, 295-299 (2019).

69. Yan, R. et al. Structural basis for the different states of the spike protein of SARSCoV-2 in complex with ACE2. Cell Res. 31, 717-719 (2021).

70. Schymkowitz, J. et al. The FoldX web server: an online force field. Nucleic Acids Res. 33, W382-8 (2005).

71. Davies, N. G. et al. Estimated transmissibility and impact of SARS-CoV-2 lineage B.1.1.7 in England. Science 372, (2021). 